GA-A16017 MASER

THE VENTING CHARACTERISTICS OF A FIBROUS THERMAL BARRIER SYSTEM DURING A RAPID DEPRESSURIZATION ACCIDENT (ROTOR FAILURE) IN AN HTGR-GT

\author{
by \\ S. LIGHTNER and W. S. BETTS, JR.
}

NOVEMBER 1980 


\section{DISCLAIMER}

This report was prepared as an account of work sponsored by an agency of the United States Government. Neither the United States Government nor any agency Thereof, nor any of their employees, makes any warranty, express or implied, or assumes any legal liability or responsibility for the accuracy, completeness, or usefulness of any information, apparatus, product, or process disclosed, or represents that its use would not infringe privately owned rights. Reference herein to any specific commercial product, process, or service by trade name, trademark, manufacturer, or otherwise does not necessarily constitute or imply its endorsement, recommendation, or favoring by the United States Government or any agency thereof. The views and opinions of authors expressed herein do not necessarily state or reflect those of the United States Government or any agency thereof. 


\section{DISCLAIMER}

Portions of this document may be illegible in electronic image products. Images are produced from the best available original document. 
This report was prepared as an account of work sponsored by an agency of the United States Government. Neither the United States Government nor any agency thereof, nor any of their employees, makes any warranty, express or implied, or assumes any legal liability or responsibility for the accuracy, completeness, or usefulness of any information, apparatus, product, or process disclosed, or represents that its use would not infringe privately owned rights. Reference herein to any specific commercial product, process, or service by trade name, trademark, manufacturer, or otherwise, does not necessarily constitute or imply its endorsement, recommendation, or favoring by the United States Government or any agency thereof. The views and opinions of authors expressed herein do not necessarily state or reflect those of the United States Government or any agency thereof. 
GA-A16017

\title{
THE VENTING CHARACTERISTICS OF A FIBROUS THERMAL BARRIER SYSTEM DURING A RAPID DEPRESSURIZATON ACCIDENT (ROTOR FAILURE) IN AN HTGR-GT
}

\author{
by \\ S. LIGHTNER and $W$. S. BETTS, JR.
}

This is a preprint of a paper to be presented at the 26th International Gas Turbine Conference, March 8-12, 1981, Houston, Texas and to be printed in the Proceedings

Work supported by

Department of Energy.

Contract DE-AT03-76SF70046

GENERAL ATOMIC PROJECT 6800 .

NOVEMBER 1980

\section{GENERAL ATOMIC COMPANY}


THE VENTING CHARACTERISTICS OF A FIBROUS THERMAL BARRIER SYSTEM DURING A RAPID DEPRESSURIZATION ACCIDENT

(ROTOR FAILURE) IN AN HTGR-GT

\author{
S. Lightner \\ General Atomlc Company \\ San Diego, Calif. \\ Assnr. Mem. ASME \\ W. S. Betts, Jr. \\ General Atomic Company \\ San Diego, Calif.
}

The thermal barrier inside the primary circuit of the direct-cycle, high-temperature gas-cooled reactor-gas turbine (HTGR-GT) may experience rapid depressurization transients. Turbine rotor fallure induces the most severe pressure transient. To determine how rotor failure affects the design adequacy of the thermal barrier, the authors experimentally examined the venting characteristics of the fibrous insulation. This paper theoretically develops a simulation technique and correlates the analytical results with test data.

\section{NOMENCLATURE}

C' Non-Darclan permeability coefficient, s

K Darcian pcrmeability coefficient, $\mathrm{m}^{2}$

P gas pressure, MPa

P1 prossure at location number $i$, where

$$
1=1,2, \ldots, 9, \mathrm{~Pa}
$$

$P_{0}$ initial pressure at start of depressurization

$\triangle P_{\text {MAX }}(\mathrm{Pl}$ - P4) MAX, maximum pressure drop across fibrous insulation and perforated tube, MPa

$\Delta \mathrm{P}_{\infty}(\mathrm{Pl}-\mathrm{P} 4)_{\infty}$, pressure drop across fibrous. insulation and perforated tube when the pressuse should be at oquilibrium, MPa

$\triangle P_{S S}$ pressure drop across seal sheet of thermal barrier, MPa

${ }^{\triangle P} \mathrm{CP}$ pressure drop across coverplate of thermal barrier, MPa

$\Delta P_{F I}$ pressure drop across fibrous insulation of thermal barrier, $\mathrm{MPa}$

R gas constant, $\mathrm{J} /(\mathrm{kg} \cdot \mathrm{K})$

$t$ time, hr

$T$ average temperature of the fibrous Inoulation, $k$.

$u$ velocity of fliow.through porous medium, $\mathrm{m} / \mathrm{s}$

$x$ distance, m

e porosity of porous medium $\mu$ viscosity of $\mathrm{gas}, \mathrm{N} \cdot \mathrm{s} / \mathrm{m}^{2}$

$\rho$ density, $\mathrm{kg} / \mathrm{m}^{3}$

$\nabla$ the vector (or del) operator $=i(\partial / \partial x)+$ $\mathrm{j}(\partial / \partial \mathrm{y})+\mathrm{k}(\partial / \partial \mathrm{z})$ in cartesian coordinates

$\nabla^{2}$ the Laplacian $=\left(\partial^{2} / \partial x^{2}\right)+\left(\partial^{2} / \partial y^{2}\right)+$ $\left(\partial^{2} / \partial z^{2}\right)$ in cartesian coordinates

\section{INTRODUCTION}

The thermal barrier of the high-temperature gas-cooled reactor (HTGR) protects the 11 ner of the prestressed concrete reactor vessel (PCRV) and the adjacent concrete from the high-temperature hellum of the primary coolant system. Th1s thermal barrier generally consists of fibrous insulation which is relalined agalnot tho liner surface by metallic coverplates and attachment fixtures. Figure 1 , shows a typical thermal barrier. The assembly includes seal sheets, located between the fibrous insulation and the metallic coverplates. These seal sheets restrict gas permeation during normal operation and contain the insulating ceramic fiber of the blankets.

This thermal barrier system must withstand environmental conditions such as pressure translents. temperatiure transients, acoustic excitation, flowinduced vibration, irradiation, and compatibility with reactor hellum. In the direct-cycle HTGR-gas turbtine ( $(n t)$ plant, the pressure translents due to turbine deblading or rotor fallures may be significantly more severe than those encountered in other types of HTGRs. Studies indicate that these pressure transients may Induce loads which could control the design of the thermal. harrier. This paper discusses the results of experimental and analytical studies to develop techniques to predict the loading on a fibrous thermal barrier system.

DISCUSSION OF PROBLEM

Due to the rapidity with which the reactor may 
depressurize during a rotor fallure accident, the pressure response of the gas within the'thermal barrier will lag the pressure changes of the primary coolant. This lag causes a pressure differential to occur across the thermal barrier. This pressure differential acts as if it were a unfform pressure load. The stresses induced by this effective pressure load in the thermal barrier coverplate and attachment fixture must be evaluated to assure design adequacy. Figure 1 indicates the components of this total pressure load $\left(\Delta \mathrm{P}_{\mathrm{T}}\right)$, and the following equation relates them to the effective, uniform pressure load:

$$
\Delta \mathrm{P}_{\mathrm{T}}=\Delta \mathrm{P}_{\mathrm{CP}}+\Delta \mathrm{P}_{\mathrm{SS}}+\Delta \mathrm{P}_{\mathrm{FI}}
$$

The flow resistance of the fibers determines the rate of insulation depressurization and, consequently, the pressure loads which will be experienced by the thermal barrier coverplate. Therefore, a simulation technique for the pressure response of the fibrous insulation needed to be verified. The results of thermal barrier rapid depressurization tests conducted at Eidgenossiches Institut fur Reaktorforschung (EIR), Wurenlingen, Switzerland, provided an opportunity to examine the simulation technique suggested in Ref. 1 .

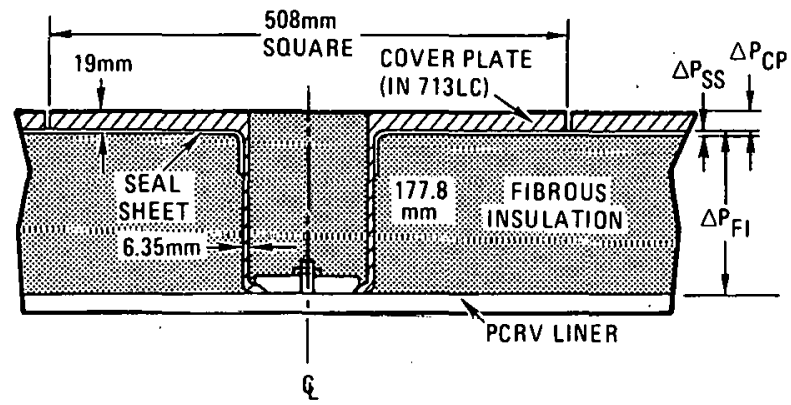

Fig.l Typical thermal barrier configuration for hot reglons of the HTGR-GT

\section{TEST .DATA INFORMATION}

EIR conducted rapid depressurization tests for a fibrous thermal insulation system. Figure 2 shows the rest arrangement. This model was filled with compressed air, then rapidly depressurized. Figure 2 also shows the locations of the piezo-electric pressure transducers which recorded the local pressure transients. These plessuit gagco wera placod at three different axial locations. For each axlal position, three pressure transducers were located as follows: within the fluiuss insulation, ingide the vent cavity, and on the inner surface of the coverplate. The pressure response of these gages was recorded as a function of time.

Experiments were conducted at three different Inttial pressure levels, which varied from -1 to 4 $\mathrm{MPa}$, and for depressurization rates from 1.2 to 400 $\mathrm{MPa} / \mathrm{s}$. Importantly, the EIR tests concluded that the axial pressure differences in the test rig were negligibl.t. This situation made one-dimensional simulation of the rest cundlliuns reasonablo. After completion of the experiments, the test rig was

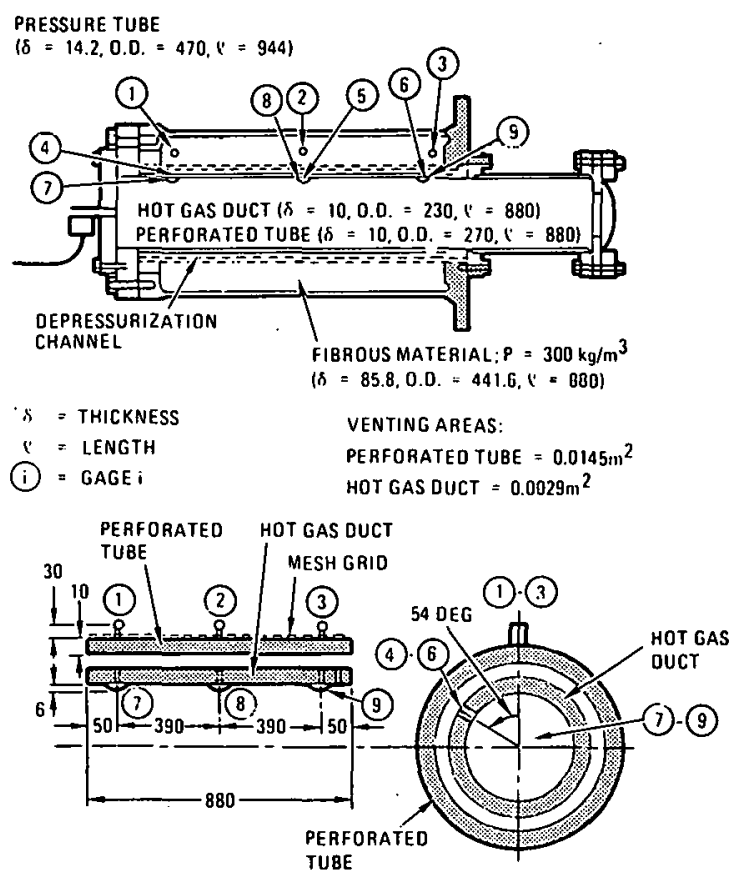

ALL DIMENSIONS ARE IN mm UNLESS OTHERWISE SPECIFIED

Fig.2 Test $\mathrm{rig}$ and locations of pressure gages 1 through 9

taken apart, and the fibrous insulation was' examined. Despite the large pressure drops across the insulation during this test, no insulation damage was detected. No displacement of the insulation and no dust from the fibrous insulation in the test assembly were detected. Compression of the fiber blankets may have occurred during the test; however, this information was not available due to the test rig 1 imitations.

\section{ANALYSIS}

Reference 1 developed a method to computersimulate pressure transients through a porous medium. This method fs hased upon the following assumptions: (1) Darcy's law is applicable; (2) the Ideal gas law is valid; and (3) low-velocity flow exists through the porous medium. Using the approach of Ref. 1 and beginning with the continuity equation,

$$
\nabla \cdot(\rho \vec{u})+\varepsilon \frac{\partial u}{\partial t}=0 .
$$

Reference 1 used Darcy's Law to find $\vec{u}$ :

$$
\vec{u}=-\frac{K}{u} \text { VP }
$$

Then Ref. 1 substituted Eq. 3 into Eq. 2 to derive a Hew form of the continuizy equalluil,

An empirical relation tor $u$ was derived frui 
the EIR test results. This empirical relationship is given in Eq. 4 below:

$$
\vec{u}=-\frac{C^{\prime}}{\rho} \nabla P \quad \text {. }
$$

Substituting Eq. 4 into Eq. 2 results in Eq. 5:

$$
\nabla \cdot\left(-C^{\prime} \nabla P\right)+\varepsilon \frac{\partial \rho}{\partial t}=0 .
$$

Using the Ideal gas $1 \mathrm{aw}$, assuming $\mathrm{T}$ to be Independent of time (1.e., isuthermal expaneion), and substituting into Eq. 5 ,

$$
\nabla \cdot\left(-C^{\prime} \nabla P\right)+\frac{\varepsilon}{R T} \frac{\partial P}{\partial t}=0 .
$$

Assuming that the porous medium is isotropic means that $C^{\prime}$ is independent of direction, and Eq. 6 becomes

$$
\nabla^{2} P=C \cdot \frac{\varepsilon}{R T} \frac{\partial P}{\partial t} .
$$

Since the EIR test results indicated that pressure differences in the axial direction were negilgible, $\mathrm{Eq}$. 7 can be rewritten in the one-dimensional form for use in a computer simulation of isothermal cases:

$$
\frac{\partial^{2} P}{\partial x^{2}}=\frac{E}{C^{\prime} R T} \frac{\partial P}{\partial t} \text {. }
$$

Using the relationship between isothermal and adiabatlc flow developed in Ref. 1 , Eq. 9 is obtalned for adiabatic cases:

$$
\frac{\partial^{2} P}{\partial x^{2}}=\frac{\varepsilon}{Y C^{\prime} R T} \frac{\partial P}{\partial t},
$$

where $\gamma=$ specific heat ratio ( 1.4 for alr). These equations were solved by using the TAC2D computer code (2). Table 1 gives transients that are reprcoontative nf conditions in the EIR tests and were gimulated using the one-dimensional TAC2D model of a radial section of the fibrous insulation in the test rig at the axlal location of gages 4 and 1. These pressure boundary conditions were 1mpressed upon the inner radial surface of the model; che other surfaces of the model were assumed to be impermeable. The properties used were

$$
\begin{aligned}
C^{\prime} & =5.86 \times 10^{-7} \mathrm{~s}, \\
\varepsilon & =0.90\left(\text { for } 300 \mathrm{~kg} / \mathrm{m}^{3} \text { Kaowoo } 1\right) \\
T & =294 \mathrm{~K}, \\
R & =287 \mathrm{~J} /(\mathrm{kg} \mathrm{K}) .
\end{aligned}
$$

This gives

$$
\frac{\varepsilon}{C^{\prime} R T}=18.2 \frac{\mathrm{s}}{\mathrm{m}^{2}} \text {. }
$$

\section{CORRELATION BETWEEN ANALYTICAL AND TEST RESULTS}

Figure 3 shows typical analytical results for the TAC2D simularion of the one-dimensional pressule response of the fibrous insulation. These results are based upon a non-Darcian permeation coefficient (C') of $5.86 \times 10^{-7}$ s. This effective permeation
TABLE 1

PRESSURE AT GAGE 4 AS USED FOR PRESSURE BOUNDARY OF THE TAC2D MODEL

\begin{tabular}{l|l|l|l|l|l|l|l}
\hline \multirow{2}{*}{$\begin{array}{l}\text { T1me } \\
\text { (ms) }\end{array}$} & \multicolumn{7}{|c}{ Pressure at P4 (MPa) (a) } \\
\cline { 2 - 7 } & HV6 & HV8 & HV10 & HV12 & HV13 & HV14 & HV15 \\
\hline 0. & 1.07 & 1.08 & 2.05 & 2.06 & 4.00 & 4.00 & 4.00 \\
3.75 & -- & -- & -- & -- & -- & -- & 4.00 \\
5. & -- & -- & -- & 1.67 & -- & -- & 3.60 \\
10. & -- & 0.80 & -- & -- & -- & -- & 3.20 \\
12.5 & -- & -- & 1.80 & 1.47 & -- & -- & -- \\
17.5 & -- & -- & -- & -- & -- & 3.00 & -- \\
20. & -- & -- & -- & -- & -- & -- & 2.65 \\
25. & 0.80 & -- & -- & -- & -- & -- & -- \\
30. & -- & -- & -- & -- & 2.99 & -- & 2.40 \\
40. & -- & -- & -- & -- & -- & -- & 2.20 \\
50. & 0.67 & 0.60 & 1.20 & 1.10 & 2.70 & 2.25 & 2.00 \\
100. & 0.48 & 0.45 & 0.85 & 0.80 & 1.90 & 1.60 & 1.50 \\
150. & -- & -- & 0.60 & - & -- & -- & -- \\
200. & 0.30 & 0.27 & 0.46 & 0.44 & 1.15 & 0.85 & 0.75 \\
300. & 0.20 & 0.17 & 0.24 & 0.23 & 0.51 & 0.50 & 0.40 \\
400. & 0.17 & 0.15 & 0.14 & 0.15 & 0.25 & 0.25 & 0.15 \\
500. & 0.17 & 0.15 & 0.10 & 0.12 & 0.15 & 0.15 & 0.10 \\
600. & 0.17 & 0.15 & 0.10 & 0.12 & 0. & -- & 0.10 \\
700. & 0.17 & 0.15 & 0.10 & 0.10 & 0. & -- & 0.10 \\
750. & 0.17 & -- & -- & -- & -- & -- & -- \\
800. & -- & 0.15 & -- & 0.10 & -- & 0.15 & -- \\
850. & -- & -- & -- & 0.10 & -- & -- & -- \\
\hline & & & & & & & \\
\hline
\end{tabular}

(a) The pressure profile is Iinear between the given data points. HVi is the case number of the individual EIR tests. The pressure profiles were intended to simulate the actual pressure experianced durting the indicated case.

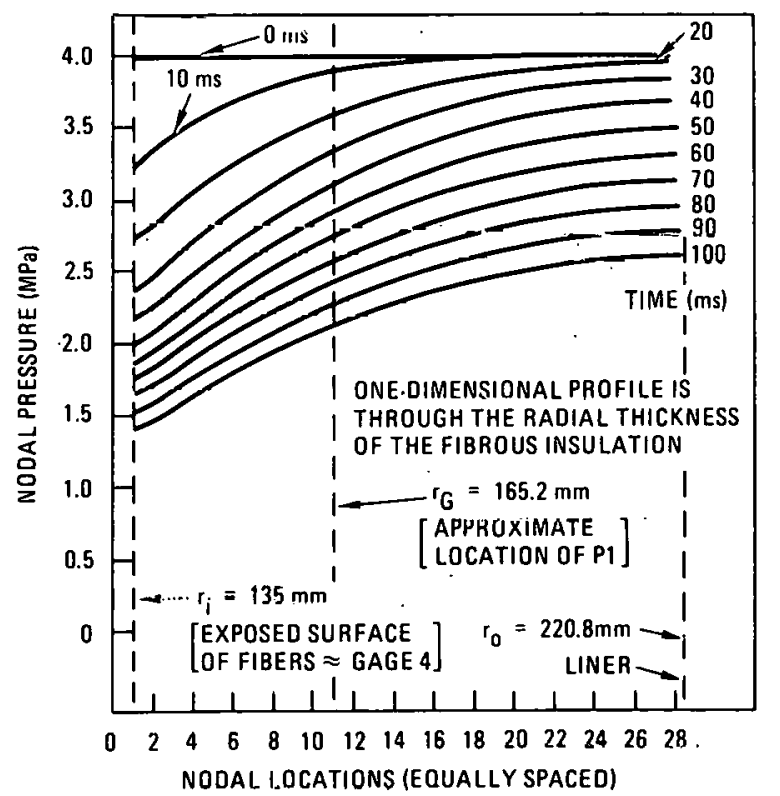

Fig.3 Transient pressure profiles for the simulation jimulation ot rase" HVIJ using isothermai flow conditions with the non-Darcian formulation 
coefficlent was derived for the fibrous insulation at $300 \mathrm{~kg} / \mathrm{m}^{3}$ density in conjunction with the mesh grid and the perforated tube, as shown in Fig. 2 . Since hand calculations showed that the flow resistance introduced in the combined system by the perforated tube was negligible and assumed true for the mesh, the non-Darcian permeation coefficlent was assumed to be representative of the behavior of the fibrous insulation.

The Fig. 3 results indicate a continuously smooth pressure distribution through the thickness of the fibrous insulation, as expected. Node 11 is the approximate radial location of gage 1 . Table 2 $g$ ives the maximum pressure drop from the inner radlal boundary to node 11 in the fibrous insulation and the time of occurrence recorded for each transient. As Table 2 shows, the measured $\triangle P_{M A X}$ and the isothermal analytical results using the non-Darcian formulation agree well. Both non-Darcian analytical simulations seem to correlate well with the maximum pressure drop (i.e., $\Delta P_{M A X}$ ). Since the isothermal analytical simulation gives a larger pressure drop than the adiabatic one, the isothermal assumption is conservative. The analytical results based on Dar$\mathrm{cy}^{\dagger} \mathrm{s}$ law do not correlate as well with the test data as the non-Darcian formulation, even though material properties and conditions were chosen to maximize the pressure drop. The results of this paper indicate that the one-dimensional response of the $f i-$ brous insulation of the thermal barrier to rapid pressure transients can be adequately simulated by $\mathrm{Eq} \cdot 8$

Table 2 gives $\Delta P_{\infty}$, the pressure difference between $\mathrm{Pl}$ and $\mathrm{P} 4$ when the test rig should be at equilibrium. $\Delta \mathrm{P}_{\infty}$ should have becn approximately 0 at the end of the recorded data. As Table 2 shows, it was not. This discrepancy was attributed to adjustinent protlema of the prassure transducers. The precise effect of the non-zero $\Delta P_{\infty}$ on the maximum pressure drop experienced during the rest is not known. However, a low estimate of $\triangle P_{M A X}$ may be reasonably assumed to be

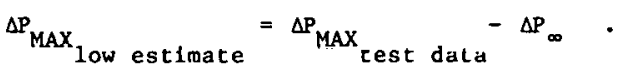

Table 2 presents important test data characteristics and case results of the analytical simulation. The $\mathrm{dP}_{4} / \mathrm{dt}$ rates given in Table 2 are the maximum values recorded for each transient. Per Eq. 8 or 9, $\triangle \mathrm{P}_{\mathrm{MAX}}$ should increase with increasing values of $\mathrm{dP4} / \mathrm{dt}$. However, Table 2 showed that this is not always the case because of the duration of the maximum $\mathrm{dP} 4 / \mathrm{dt}$. For example, HV 8 had a dP4/dt of $28.3 \mathrm{MPa} / \mathrm{s}$ for the first $10 \mathrm{~ms}$, which then decreased to $5 \mathrm{MPa} / \mathrm{s}$ during the next $40 \mathrm{~ms}$; for $\mathrm{HV} 6, \mathrm{dP} 4 / \mathrm{dt}$ was $11.1 \mathrm{MPa} / \mathrm{s}$ for $25 \mathrm{~ms}$ and $5.2 \mathrm{MPa} / \mathrm{s}$ for the next $25 \mathrm{~ms}$. The average $\mathrm{dP} 4 / \mathrm{dt}$ for the first $50 \mathrm{~ms}$ of HV8 was $9.7 \mathrm{MPa} / \mathrm{s}$, which $1 \mathrm{~s}$ close to the value of $8.3 \mathrm{MPa} / \mathrm{s}$ for the first $50 \mathrm{~ms}$ of HV6. Therefore, the maximum pressure drops for the non-Darcian analytical simulation depend on the magnitude and duration of the depressurization rates.

Figure 4 compares the pressure response of the fibrous insulation during case HV15 with the nonDarclan analytical results. As Fig. 4 shows, the analytical simulation predicts lower pressures than were recorded during the test. This could be attributed to either a variation of the empirically derived $C^{\prime}$ or the compression of the fibrous insulation against the perforated tube during the depressurization. The $C^{\prime}$ was assumed to be a constant for all cases considered. Parametric variation of $C^{\prime}$ could be used to attexpt better correlation with the test data. Such work was not feasible during this study.

APPLICATIONS OF EQ. 8 TO A TYPICAL THERMAL BARRIER COVERPLATE

The techniques which were empirically verified in this study estimated the pressure load on the

TABLE 2

COMPARISON OF TEST DATA AND ANALYTICAL SIMULATION

\begin{tabular}{|c|c|c|c|c|c|c|c|c|c|c|c|c|}
\hline \multirow[b]{4}{*}{$\begin{array}{c}\text { Case (a) } \\
\text { No. }\end{array}$} & \multirow[b]{4}{*}{$\begin{array}{l}\mathrm{Po}_{\mathrm{O}} \\
(\mathrm{MPa})\end{array}$} & \multirow[b]{4}{*}{$(\mathrm{dP} 4 / \mathrm{dt})_{\mathrm{MAX}}{ }^{(\mathrm{b})}$} & & & & & \multicolumn{6}{|c|}{ Analytical Results of $\Delta P_{M A X}$} \\
\hline & & & & & & & \multicolumn{4}{|c|}{$\begin{array}{l}\text { Non-Darcian(c) } \\
\text { Formulation }\end{array}$} & \multirow{2}{*}{\multicolumn{2}{|c|}{$\begin{array}{c}\text { Darcy's Law }(d) \\
\text { Formulation } \\
\text { Isothermal }\end{array}$}} \\
\hline & & & \multicolumn{4}{|c|}{ Test Results } & \multicolumn{2}{|c|}{ Isothermal } & \multicolumn{2}{|c|}{ Adiabatic } & & \\
\hline & & & $\begin{array}{l}\Delta \mathrm{P}_{\mathrm{MAX}} \\
(\mathrm{MPa})\end{array}$ & $\begin{array}{c}\text { T1me of } \\
\Delta \mathrm{P}_{\mathrm{MAX}} \text { (ms) }\end{array}$ & $\begin{array}{c}\Delta \mathrm{P}_{\infty} \\
(\mathrm{MPa})\end{array}$ & $\underset{(\mathrm{MPa})}{\Delta \mathrm{P}_{\mathrm{MAX}}-\Delta \mathrm{P}_{\infty}}$ & (MPa) & $\begin{array}{l}\text { Tlme } \\
\text { (ms) }\end{array}$ & (MPa) & $\begin{array}{l}\text { Time } \\
\text { (ms) }\end{array}$ & (MPa) & $\begin{array}{l}\text { Time } \\
\text { (ms) }\end{array}$ \\
\hline HV8 & 1.08 & 28.3 & 0.23 & $\sim 20$ & 0.05 & 0.16 & 0.23 & 12 & 0.22 & 12 & - & -- \\
\hline HV12 & 2.06 & 78.6 & 0.49 & 25 to 40 & 0.17 & 0.33 & 0.48 & 14 & 0.44 & 14 & 0.30 & 12 \\
\hline HV 13 & 4.00 & 26.2 & 0.65 & 75 to 100 & 0.30 & 0.35 & 0.65 & 30 & 0.58 & 30 & 0.20 & 30 \\
\hline $\operatorname{lIV} 14$ & 4.01 & 57.2 & 0.90 & 50 to 75 & 0.30 & 0.60 & 0.85 & 50 & 0.75 & 50 & -- & - \\
\hline HV 15 & 4.00 & 80.0 & 1.16 & 50 to 75 & 0.30 & 0.90 & 0.95 & 30 & 0.85 & 30 & - & -- \\
\hline HV6 & 1.08 & 11.1 & 0.17 & $\sim 50$ & 0.03 & 0.15 & 0.19 & 26 & 0.17 & 26 & 0.14 & 26 \\
\hline HVIO & 2.06 & 20.0 & 0.36 & -70 & 0.15 & 0.24 & 0.45 & 50 & 0.38 & 50 & -- & - \\
\hline
\end{tabular}

(a) HVI is the case number of Individual EIR test.

(b) Maximum depressurization rate given in the EIR data for P4. Estimated to be the maximum depressurization rate of flow out of fibrous insulation.

(c) Non-Darcian fordulation l.s hased on $\vec{u}-\left(-C^{\prime} / p\right) /(\partial P / \partial x)$.

(d) Using $K=2.32 \times 10^{-12} \mathrm{~m}^{2}$. This value appears approximately an order of magnitude lower chull wust data would indicate. However, it was assumed low so that the calculated $\triangle P_{M A X}$ would be closer to the test results. 


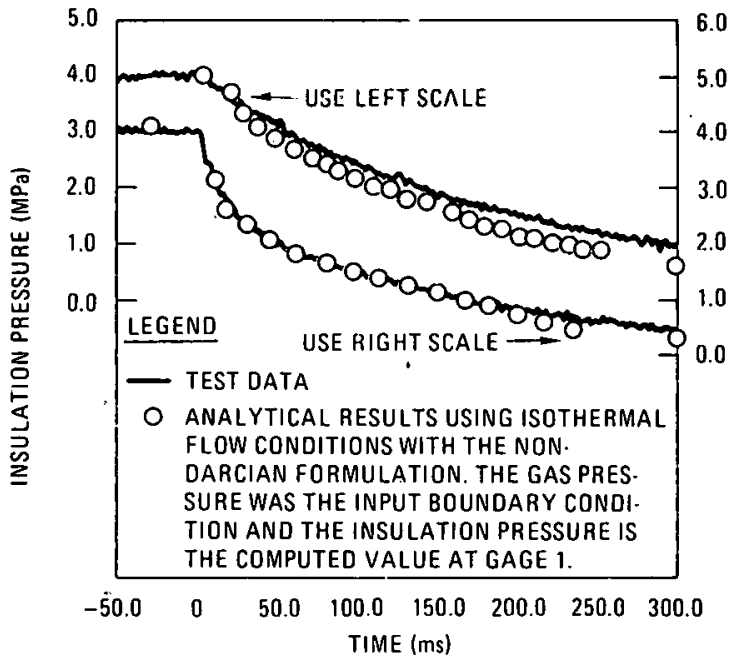

F1g.4 Comparison of test data and analytical results for case HVIS

thermal barrier during a turbine rotor failure from an assumed $142 \%$ overspeed accident. This postulated transient has the highest depressurization rate (1.e., $\sim 77 \mathrm{MPa} / \mathrm{s}$ ) for the HTGR-GT and is, therefore, the controlling depressurization transient for the thermal barrier.

The total pressure load $\left(\Delta P_{T}\right)$ acting upon the coverplate is the sum of the pressure drops across the fibrous insulation, seal sheet, and coverplate, as given hy F.g. 1 ,

Solving Eq. 8 with TAC2D for a $159.0-\mathrm{mm}(6.2 \mathrm{~b}$ in.) thick fibrous insulation, the maximum pressure drop due to the fibers ylelied $\Delta P_{F I}=0.59 \mathrm{MPa}$.

This pressure load is an order of magnitude larger than the sum of $\Delta P_{S S}$ and $\Delta P_{C P}$, as estimated in another study. The resulting total pressure drop $\Delta \mathrm{P}_{\mathrm{T}}$ is sufficiently high to control the design of the thermal barrier.

\section{COMCLUS ION3}

This study has verified with test data that, for lapid depresourization, the relationship

$$
u=\frac{-C^{\prime}}{\rho} \frac{\partial P}{\partial x}
$$

1s more applicable than Darcy's law for predicting the one-dimensional motion of a gas as 1 t escapes [ 'uï a fibrouc lnsulatinn. When Eq. 12 was combined with the continuity equation and an assumption of isothermal flow was made, Eq. 8 resulted.

Whon Eq, 8 was sol.ved for cases representative of experimental conditions, the predicted pressure response of the insulation correlated well with the test data. However, notably, this correlation was only for air with a single initial temperature. This implies that during the test the viscosity ( $\mu$ ) of the gas would have remalned constant. Consequently, a viscosity relationslifp possibly chould be Included in Eqs. 12 and 8 .

The application of Eqs. 8 and 1 in evaluating Lite thermal barripr of the HTGR-GT has shown that the pressure drop induced by the venting of the fibrous insulation during a rapid pressure transient is more controlling than the pressure drop due to the flow resistance of the coverplate or seal sheets. The loads induced by the most severe pressure tiatisient for the HTCR-GT ware estimated. These loads were found to be high enough to control the thermal barrier design in the regions of the primary loop with severe depressurization rates.

\section{ACKNOWLEDGMENTS}

The authors gratefully acknowledge permission by the Eidgenossiches Institut fur Reaktorforschung to utilize subject experimental data. Special acknowledgment is given Dr. H. Weber (EIR) for his assistance during the data phase. Ihis work was supported by the Department of Energy under Contract DE-AT03-76SF0046.

\section{REFERENCES}

1 Morrison, F., "Transtent Compressible Flow in Porous Med1a," UCID-15914, Aug. 27, 1971, Lawrence Livermore Radiation Laboratory, University of California, Livermore, Calif.

2 Boonstra, R. H., "TAC2D, A General Purpose Two-Dimensional Heat Transfer Computer Code - User's Manual," GA-A14032, July 15, 1976, General Atomic Company, San Diego, Calif. 


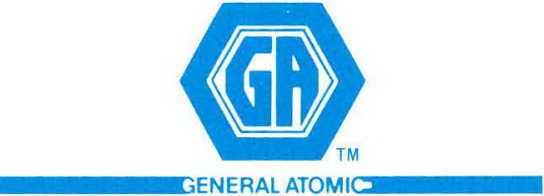

GENERAL ATOMIC COMPANY P. O. BOX 81608

SAN DIEGO, CALIFORNIA 92138 